\title{
High incidence of Meckel's syndrome in Gujarati Indians
}

\author{
I D YOUNG*, A B RICKETT*, ANDM CLARKE† \\ From the Departments of Child Health* and Community Health†, University of Leicester, Leicester.
}

SUMMARY Five probable cases of Meckel's syndrome have been ascertained retrospectively through the Leicestershire Perinatal Mortality Survey for the years 1976 to 1982. All of these babies were born to Hindu parents originating from the Gujarat State in India, suggesting that Meckel's syndrome is particularly common among this ethnic group, with a gene frequency of approximately $0 \cdot 028$.

Meckel's syndrome, also known as dysencephalia splanchnocystica or the Meckel-Gruber syndrome, is a lethal disorder characterised by the classical triad of occipital encephalocele, polycystic kidneys, and postaxial polydactyly. It takes its name from Johann Friedrick Meckel who described affected sibs in 1822..$^{1}$ This condition was established as a distinct entity in contemporary publications in $1969^{2}$ and subsequently shown to be autosomal recessive in inheritance. ${ }^{34}$

Associated abnormalities include facial clefting, microphthalmia, congenital heart defects, ambiguous or hypoplastic genitalia, and talipes. ${ }^{3}$ Conventionally, the diagnosis is based on the presence of normal chromosomes and at least two of the three cardinal abnormalities, although it has been suggested following review of affected sibs of probands that diagnostic criteria should include cystic renal dysplasia plus at least two other defects. ${ }^{5}$

In this paper the authors present evidence which indicates that the gene frequency of Meckel's syndrome is particularly high in the Leicestershire Asian Hindu community originating from the $\mathrm{Gu}$ jarat State in western India.

\section{Case reports}

The following cases were ascertained through the records of the Leicestershire Perinatal Mortality Survey for the years 1976 to 1982 inclusive. This continuing survey, details of which have been published elsewhere ${ }^{6}$ records information about all babies dying in the perinatal period in Leicestershire. The survey is organised through the Depart-

Received for publication 20 August 1984. Accepted for publication 3 October 1984. ment of Community Health in collaboration with the Department of Obstetrics and Gynaecology.

In total, five probable cases of Meckel's syndrome, all occurring in non-Caucasian babies, were ascertained. There was only one possible case among Caucasian births.

CASE 1

This female infant was born in 1976. She was delivered by Caesarean section following antepartum haemorrhage at 42 weeks. Birth weight was $3.60 \mathrm{~kg}$ and the placenta weighed $660 \mathrm{~g}$. The infant is recorded as having gasped a few times with no measurable Apgar score. Documented abnormalities included anencephaly, cleft lip and palate, polydactyly involving the left hand and both feet, and an 'imperforate vulva'. Chromosome and necropsy studies were not performed. This child was the product of the second pregnancy of healthy unrelated Hindu parents originating from different villages in the Surat district in the southern part of the Gujarat State. The first pregnancy resulted in a healthy male infant and the third pregnancy constitutes case 2 .

CASE 2

This female infant was born in 1981. She was delivered at 32 weeks with birth weight $1.63 \mathrm{~kg}$ and lived only a few minutes. External abnormalities included microcephaly, an encephalocele, bilateral cleft lip and palate, abdominal distension, bilateral talipes, hexadactyly of the right hand and both feet, and septadactyly of the left hand. Chromosomes showed a normal female karyotype.

Additional abnormalities noted at necropsy were aniridia of the right eye, left microphthalmia, incomplete fusion of the tip of the mandible, a 
distended choledocal cyst, a small accessory spleen, large polycystic kidneys with ureteric insertions on the anterior surface of the kidneys, and a small paraovarian cyst. A midline cleft was noted in the occipital bone and the cerebral sulci and gyri were poorly developed.

\section{CASE 3}

This female infant was born in 1977. She was delivered by Caesarian section because of fetal distress following induction of labour with a breech presentation at term. Birth weight was $3.08 \mathrm{~kg}$ and the placenta weighed $580 \mathrm{~g}$. The baby lived for five minutes. Abnormalities included an occipital encephalocele, cleft palate, and postaxial polydactyly of all four limbs. At necropsy the liver was described as 'cystic' and the kidneys were noted to be large. Chromosome studies were not performed. This baby was the product of the first pregnancy of healthy unrelated Hindu parents originating from the city of Jamnagar in West Gujarat. The second pregnancy resulted in a spontaneous first trimester miscarriage and the third in a normal male infant.

\section{CASE 4}

This male infant was born in 1980 . He was delivered by Caesarian section following an antepartum haemorrhage at 33 weeks. Birth weight was $1.74 \mathrm{~kg}$ and the placenta weighed $460 \mathrm{~g}$. There were only two vessels in the umbilical cord. The baby lived for two hours. Abnormalities noted at birth included microcephaly, a ruptured occipital encephalocele, arthrogrypotic limbs with polydactyly of both hands and the right foot, bilateral talipes equinovarus, and abdominal distension. Chromosome studies showed a normal male karyotype. At necropsy the kidneys were enlarged and polycystic, each weighing $380 \mathrm{~g}$. The brain was noted to be small. This baby was the

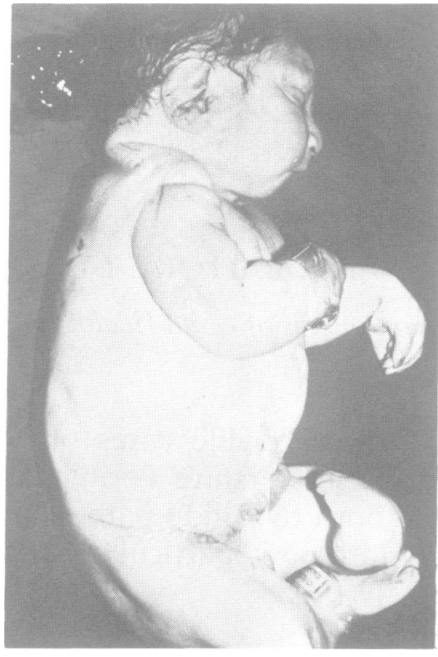

FIGURE Post mortem view of case 5.

product of the second pregnancy of healthy unre- or lated Hindu parents originating from large towns approximately 70 miles apart in West Gujarat. The previous pregnancy had resulted in a normal male infant.

\section{CASE 5}

This male infant was born in 1982 . He was born at $\overrightarrow{\overrightarrow{0}}$ term and lived 20 minutes. Birth weight was $2.72 \mathrm{~kg}$ and the placenta weighed $460 \mathrm{~g}$. Abnormalities noted at birth included (figure) a ruptured occipital encephalocele, microcephaly, micrognathia, a widely separated sagittal suture, posterior central cleft palate, arthrogrypotic limbs with postaxial hexadactyly of both feet and the left hand, and postaxial

TABLE Documented abnormalities in the five cases.

\begin{tabular}{|c|c|c|c|c|c|}
\hline & Case I & Case 2 & Case 3 & Case 4 & Case 5 \\
\hline Sex & $\mathbf{F}$ & $\mathbf{F}$ & $\mathrm{F}$ & M & $\mathbf{M}$ \\
\hline Gestation (wk) & 42 & 32 & 40 & 33 & 40 \\
\hline Birth weight $(\mathrm{kg})$ & $3 \cdot 60$ & $1 \cdot 63$ & $3 \cdot 08$ & 1.74 & $2 \cdot 72$ \\
\hline Survival & $<5 \min$ & $<5 \mathrm{~min}$ & $5 \mathrm{~min}$ & $2 \mathrm{~h}$ & $20 \mathrm{~min}$ \\
\hline Occipital encephalocele & & + & + & + & + \\
\hline Anencephaly & + & & & & \\
\hline Ocular abnormalities & & + & & & \\
\hline Cleft lip/palate & + & + & + & & + \\
\hline \multicolumn{6}{|l|}{ Polydactyly } \\
\hline $\mathbf{R}$ hand & & + & + & + & ++ \\
\hline $\mathrm{L}$ hand & + & ++ & + & + & + \\
\hline$R$ foot & + & + & + & + & + \\
\hline $\mathrm{L}$ foot & + & + & + & & + \\
\hline Polycystic kidneys & & + & \pm & + & \pm \\
\hline Abnormal genitalia & + & & & & + \\
\hline $\begin{array}{l}\text { Chromosomes } \\
(\mathrm{N}=\text { normal })\end{array}$ & $?$ & $\mathrm{~N}$ & $?$ & $\mathrm{~N}$ & $\mathrm{~N}$ \\
\hline
\end{tabular}


septadactyly of the right hand. Enlarged kidneys could be easily palpated through a lax abdominal wall. The genitalia were ambiguous with absent phallus and empty scrotal sac. Chromosome studies revealed a normal male karyotype. Permission for necropsy was refused. This baby was the second child of healthy unrelated Hindu parents originating from the city of Jamnagar in West Gujarat. The first pregnancy resulted in a healthy male infant.

Three of these four families are of different caste and there is no known interrelationship. All of these mothers have different maiden names. Three of the families came to the United Kingdom via East Africa, two from Uganda and one from Kenya.

The relevant clinical and pathological findings in the five cases are summarised in the table.

\section{Incidence of Meckel's syndrome}

During the years 1976 to 1982 inclusive, there was a total of 80210 live and stillbirths with gestation greater than 28 weeks in Leicestershire. Of these, 9588 were to mothers of Asian origin. It is not known how many of these mothers originated from Gujarat, but it is known that $68 \%$ of all Leicester Asians are Gujarati* and there is no reason to believe that the number of Gujarati births will have differed significantly from $68 \%$ of 9588 that is, 6520 . Thus the incidence of Meckel's syndrome among Gujarati births during that period was approximately 1 in 1304 .

Given that this disorder is autosomal recessive and assuming that Hardy-Weinberg equilibrium has been achieved, the gene frequency q equals approximately 0.0277 or 1 in 36 . Therefore the frequency of heterozygotes equals approximately 1 in 18 .

The standard error of this estimate of $\mathrm{q}$ equals

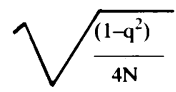

where $\mathrm{N}$ equals the total number of Gujarati births. ${ }^{7}$ Thus the standard error of $q$ equals 0.0062 so that the $95 \%$ confidence limits for $q$ equal $0.0277 \pm$ 0.0122 .

\section{Discussion}

Of the five cases described in this paper the diagnosis of Meckel's syndrome can be firmly accepted by any criteria in cases 2 and 4 . The diagnosis in case 1 can be regarded as highly probable since this baby was a sib of case 2 and

*Distribution of Ethnic Minorities in Leicester. Report of the Leicester Council for Community Relations 1978. anencephaly has been well documented in this disorder. ${ }^{5}$ In case 5 the withholding of permission for necropsy prevented confirmation that the enlarged palpable kidneys were indeed polycystic, but the clinical features and photographic evidence all indicate that this baby had Meckel's syndrome. The diagnosis in case 3 is less well established with no definite record of polycystic kidneys and no chromosome studies. However, the kidneys were noted to be large and the liver was 'cystic' so that Meckel's syndrome clearly features prominently in the differential diagnosis. Although survival beyond the perinatal period has been recorded in Meckel's syndrome ${ }^{8}$ this is very unusual, so that it is unlikely that any cases have been missed in the population under study.

Information on the incidence of Meckel's syndrome in other populations is scanty but several authors have suggested that the disorder is likely to be much more common than is generally realised. In Finland 28 cases were ascertained 'without active search' and the authors claimed to have knowledge of many other probable cases, ${ }^{9}$ although in retrospect some of these may have had the hydrolethalus syndrome, which is relatively common in Finland. ${ }^{10}$ The incidence among Jews in Israel is deemed to be at least 1 in $50000 .{ }^{19}$ In Boston eight cases, at least five of which were Caucasian, were identified among 106000 newborns, giving an incidence of 1 in $13250,{ }^{12}$ and in Belgium three cases, all Caucasian, were observed among 10224 births, an incidence of 1 in $3408 .^{13}$ Meckel's syndrome has also been recorded in patients of Pakistani origin ${ }^{14}$ and in Arabian ${ }^{15}$ and Indian ${ }^{16}$ reports.

It is difficult to explain the high incidence of Meckel's syndrome observed in the Leicestershire Asian community. It is very unlikely that a founder effect or inbreeding or both can be implicated, as in the Hutterites, ${ }^{17}$ since the families originate from different parts of the Gujarat State, the mothers have different maiden names, consanguinity is denied, and Hindu custom firmly discourages inbreeding. Alternative explanations include a high mutation rate (equal to the incidence of the disorder since the fitness equals zero), heterozygote advantage (equal to approximately $2.85 \%$ ), or heterogeneity. It is well recognised that there is considerable phenotypic overlap between Meckel's syndrome and other conditions, such as the hydrolethalus and Smith-Lemli-Opitz syndromes, ${ }^{i \bar{B}}$ and possible genetic heterogeneity within Meckel's syndrome itself has been considered. ${ }^{19}$

The authors would welcome correspondence with regard to whether Meckel's syndrome has been observed in Asian communities in other parts of Britain and elsewhere. In the meantime the import- 
ance of recognising this disorder is stressed in view of its associated $25 \%$ recurrence risk and the availability of antenatal diagnosis through ultrasonography and alphafetoprotein assay. ${ }^{13} 20$

\section{Addendum}

Since submitting this paper, the proceedings of the first Meckel Symposium have been published. Evidence presented at this Symposium suggested that the frequency of the Meckel syndrome gene is relatively high among the Tartar population in the Soviet Union, ${ }^{21}$ and that when studied prospectively the incidence of Meckel's syndrome in Finland was approximately 1 in $8500 .^{22}$ No information was presented concerning the incidence of Meckel's syndrome in the Indian subcontinent.

The authors wish to thank Mrs G Ahmed, Mrs S Kenney, and Miss E Mason for their help with this study. The Leicestershire Perinatal Survey is funded by the Leicestershire Health Authority.

\section{References}

I Meckel JF. Beschreibung zweier durch sehr ähnliche Bildurgsabweichungen entstellter Geschwister. Dtsch Arch Physiol 1822;7:99-172.

2 Opitz JM, Howe JJ. The Meckel syndrome (dysencephalia splanchnocystica, the Gruber syndrome). Birth Defects 1969;XIII(3D):267-72.

${ }^{3}$ Mecke S, Passarge E. Encephalocele, polycystic kidneys and polydactyly as an autosomal recessive trait simulating certain other disorders: the Meckel syndrome. Ann Genet (Paris) 1971;14:97-103.

${ }^{4}$ Hsia YE, Bratu M. Herbordt A. Genetics of the Meckel syndrome (dysencephalia splanchnocystica). Pediatrics $1971 ; 48: 237-47$.

${ }^{5}$ Fraser FC, Lytwyn A. Spectrum of anomalies in the Meckel syndrome, or: "maybe there is a malformation syndrome with at least one constant anomaly". Am J Med Genet 1981;9:67-73.

- Clarke M, Clayton DG. Quality of obstetric care provided for Asian immigrants in Leicestershire. Br Med J 1983;286:621-3.
${ }^{7}$ Emery AEH. Methodology in medical genetics. An introduction $\stackrel{?}{\rightarrow}$ to statistical methods. Edinburgh, London, New York: Churchill $\overline{\bar{F}}$ Livingstone, 1976.

${ }^{x}$ Lowry RB, Hill RH. Tischler B. Survival and spectrum of anomalies in the Meckel syndrome. Am J Med Genet 1983;14:417-21.

${ }^{9}$ Norio R, Aula P, Rapola J. Meckel syndrome. In: Eriksson $\overparen{\mathbb{\Phi}}$ AW, Forsius HR, Nevanlinna HR, Workman PL, Norio RK, eds. Population structure and genetic disorders. London, New York: Academic Press, 1980: 637-9.

10 Salonen R, Herva R, Norio R. The hydrolethalus syndrome: dclineation of a 'new' lethal malformation syndrome based on 28 patients. Clin Genet 1981:19:321-30.

1 Fried K. Relatively high prevalence of the Meckel syndromes among Jews. Isr J Med Sci 1973;9:1399.

12 Holmes LB, Driscoll SG, Atkins L. Etiologic heterogeneity of neural tube defects. $N$ Engl J Med 1976;294:365-9.

${ }_{13}$ Moerman P, Verbeken E, Fryns JP, Goddeeris P, Lauweryns JM. The Meckel syndrome. Pathological and cytogenetic $\omega$ observations in eight cases. Hum Genet 1982;62:240-5.

${ }^{14}$ Crawfurd Md'A, Jackson P. Kohler HG. Meckel's syndrome (dysencephalia splanchno-cystica) in two Pakistani sibs. J Med 윽 Genet 1978:15:242-5.

15 Haque KN, Zaidi M. Dysencephalia splanchnocystica (Meckel's syndrome). Report of two cases and review of literature. Saudic Med J 1981:2:61-4.

16 Bhandari B, Mandowara SL, Mehta R. Meckel Gruber syn- $\frac{\overline{9}}{9}$ drome (dysencephalia splanchnocystica). Indian Pediatr $\vec{\bullet}$ 1981:18:760-1.

17 Schurig V. Bowen P. Harley F. Schiff D. The Meckel syndrome or in the Hutterites. Am J Med Genet 1980;5:373-81.

18 Lowry RB. Variability in the Smith-Lemli-Opitz syndrome: overlap with the Meckel syndrome. Am J Med Genet 1983;14:429-33.

${ }^{19}$ Seller MJ. Phenotypic variation in Meckel syndrome. Clin Genet 1981;20:74-7.

20) Seller MJ. Meckel syndrome and the prenatal diagnosis of neural tube defects. J Med Genet 1978;15:462-5

${ }^{21}$ Lurie IW, Prytkov AN, Meldere LV. Meckel syndrome in 3 different populations. Am J Med Genet 1984;18:661-9.

22 Salonen R, Norio R. The Meckel syndrome in Finland: epidemiologic and genetic aspects. Am J Med Genet 1984; 18:691-8.

Correspondence and requests for reprints to Dr I D Young, Department of Child Health, Clinical Scien- 3 ces Building, PO Box 65, Leicester Royal Infirmary, Leicester LE2 7LX. 